\title{
Volatile organo-selenium speciation in biological matter by solid phase microextraction-moderate temperature multicapillary gas chromatography with microwave induced plasma atomic emission spectrometry detection
}

\author{
C. Dietz, J. Sanz Landaluze, P. Ximénez-Embún, Y. Madrid-Albarrán, C. Cámara* \\ Department of Analytical Chemistry, Faculty of Chemistry, University Complutense de Madrid, Ciudad Universitaria, 28040 Madrid, Spain
}

Received 27 May 2003; received in revised form 15 September 2003; accepted 18 September 2003

\begin{abstract}
Microwave induced plasma atomic emission spectrometry (MIP-AES) in combination with multicapillary (MC) gas chromatography could be proven to be useful for element specific detection of volatile species. Solid phase microextraction (SPME) was used for preconcentration and sample-matrix separation. The fiber desorption unit as well as the heating control for the MC column were in-house developed and multicapillary column was operated at moderate temperatures $\left(30-100^{\circ} \mathrm{C}\right.$ ). The method was optimized for organo-selenium species (dimethylselenide (DMSe), diethylselenide (DEtSe) and dimethyldiselenide (DMDSe)), using a chemometric approach. Stationary phases for the separation column were optimized using a conventional GC and contrasted with the results obtained with the MC. Application was focussed on selenium accumulating biological matter, such as lupine, yeast, Indian mustard and garlic. These samples were grown in hydroponic solution containing inorganic selenium $\left(\mathrm{Na}_{2} \mathrm{SeO}_{3}\right.$ and $\left.\mathrm{Na}_{2} \mathrm{SeO}_{4}\right)$. SPME sampling was carried out in fixed volume flow boxes in headspace above the living plants and in vials using treated samples. Results demonstrate inorganic selenium transformation into volatile organic species during metabolism. Separation is fast, a chromatogram can be obtained in less than 3 min and detection limits were at sub-ppb level for all investigated species. The system is independent from the use of a conventional gas chromatographic oven and can be used as a versatile alternative to highly cost intensive methods such as GC-ICP-MS.
\end{abstract}

Keywords: Solid phase microextraction; Microwave induced plasma emission spectroscopy; Organo-selenium compounds; Multicapillary columns; Lupine; Yeast; Indian mustard; Garlic; Chemometrics

\section{Introduction}

Regarding its clinical and environmental effects, selenium is one of the most challenging elements. Due to the ambivalent behavior of selenium compounds, ranging from being essential to highly toxic [1], depending on the species, oxidation state and concentration, there is an evident interest in determination of the selenium content in a wide range of environmental matrices, such as air, water, biological tissue and sediments. Release of selenium into the environment as a result of human activities was estimated to be $79.000 \mathrm{t}$ per year in 1988 [2], with a clear increasing tendency since then [3]. This fact is due to its use in fast growing industrial sectors, such as microelectronics, Xerox, semiconductors and optoelectronics. Organic selenium species in biological and environmental matter are likely to be generated from bioalkylation processes, similar to those established for $\mathrm{Hg}, \mathrm{Pb}, \mathrm{As}$ and $\mathrm{Sn}$ [4]. These transformations are probably caused by bacteria and micro-organisms; other sources for organo-selenium species may be animal exhalation from seleno-protein degradation and metabolites of inorganic selenium absorbed by plants $[5,6]$. All these processes generate volatile and less toxic species; inorganic selenium species like selenite are found to be up to 500 times more toxic than common organo-compounds [7]. These volatile organo-selenium species are likely to be released into the atmosphere [8] and thus form an important part in the global cycling of this element. In between the most abundant 
organic species in environmental and biological samples are volatile methylselenides (dimethylselenide (DMSe), dimethyldiselenide (DMDSe)); others frequently found are trimethyl-selenonium ion and several seleneoaminoacids (selenomethionine, selenocysteine) [9].

Plants show considerably different physiological responses to selenium [10]. Some plant species have the ability to accumulate large amounts of selenium without showing symptoms of toxicity, among them the plants under investigation in the present work. These species have been applied for the bioremediation of large scale Se-contaminated sites, soil and water [11], in a natural process called phytoremediation [12]. It involves uptake of selenium from the growth medium (phytoextraction), biotransformation processes and emission of volatile selenium species (phytovolatilization). A deeper insight in the mechanisms of metal metabolism by different plant species could help to substantially improve the state of art in phytoremediation techniques. This includes as well detection of species emitted by the plant as the attempt of identifying the form in which the element may be present in different parts of the plant, such as root, stem, leaves, etc.

The most common approach for volatile organo-selenium determination involves a preconcentration step by cryogenic trapping, followed either by thermal desorption or extraction using an organic solvent, prior to detection by mass spectrometry $[13,14]$ or emission spectroscopy $[15,16]$. Since SPME was introduced as a sampling technique in the early 1990s [17], the interest and number of publications constantly increased, especially in the environmental field [18], food analysis [19], clinical [20], botanical [21] and forensic [22] applications, focussed on organic compounds as target analyte. More recently, application of SPME has been extended to the field of trace metal speciation, basically after analyte alkylation prior to separation by GC, coupled with different detectors [23]. By far the most popular elements determined with this method are tin, lead and mercury. In selenium determination SPME has been used for inorganic selenium speciation, using either ethylation [24] or acid microwave digestion [25] for volatile species generation, coupled in both cases with GC-MS detection. Seleno-aminoacids like selenomethionine, selenoethionine and selenocystine were determined by Caruso's group [26], after derivatization using SPME and GC-ICP-MS coupling. Emphasis was stressed on optimization of polydimethylsiloxane (PDMS) coating obtained by a modified sol-gel fiber treatment [27]. The same group performed determination of several volatile alkyl-selenides and their sulphur analogues by SPME-GC-ICP-MS [28]. Application was focussed on selenium metabolism in Brassica juncea seedlings, finding that the primary volatiles measured in headspace were DMSe and DMDSe.

SPME presents several advantages when used for sample preparation, such as sample-matrix separation, no need for use of solvents, reduced extraction time and avoidance of contamination. On the other hand some drawbacks have to be taken into account, basically reproducibility and problems related to the great amount of variables involved in method optimization. For elevated confidence and quality of the results, the optimization of all variables involved in the analysis is fundamental $[29,30]$. When using the classical univariate approach for method optimization, which is the systematic alteration of a single variable whilst maintaining the other key parameters constant, although valuable conclusions can be drawn, possible synergetic effects and the combination of variables cannot be properly evaluated. Apart from that, this method is tedious and time consuming, due to the elevated number of experiments that have to be carried out. The use of an experimental design (e.g. full factorial, fractional factorial, Plackett and Burman designs, central composite, face-centered cube, routable central composite, Doehlert, etc.) combined with analysis of variance is much more confident, avoids the above mentioned limitations, but, surprisingly, is still not extensively used in analytical applications. Multivariate methods involve simultaneous combinations of a number of parameters allowing evaluation of interdependence of variables, influence on response and optimization of these influential factors.

The present paper addresses the use of a novel and fairly simple instrumental approach, MC-MIP-AES for organoselenium detection in selenium accumulating biological matter, such as lupine, yeast, Indian Mustard and garlic. As sample introduction in microwave induced plasma discharges is critical [31,32], SPME is used as an attractive and alternative method for sample preparation, compatible with stable MIP operation. Optimization of instrumental and analytical parameters is carried out applying chemometrics, like the use of an experimental design and analysis of variance.

\section{Experimental}

\subsection{Instrumentation}

The system consists in analyte desorption from a loaded SPME fiber, separation by multicapillary gas chromatography, a microwave induced plasma excitation source and optical emission spectroscopic detection. Fig. 1 presents an overview of the analytical system. The SPME fiber desorption unit was in-house developed in order to provide temperature control during the desorption step and to be independent of a GC injection port. Basically it consists of a brass heater block with a GC glass liner (Supelco) inserted, where desorption of analytes sorbed onto the fiber takes place. Details of the system are given elsewhere [33]. The outlet of desorption unit was connected to a straight $25 \mathrm{~cm}$ multicapillary column (BeeChrom OV-17 50\% phenyl-50\% methylpolysiloxane, $n \approx 1000$, i.d. $40 \mu \mathrm{m}$, film thickness $0.2 \mu \mathrm{m}$ ). The column was housed in a stainless steel tube with graphite sealed fittings, electrically isolated by a $4 \mathrm{~mm}$ i.d. glass tubing which was surrounded by a coil of Nichrome wire. The latter was heated by the means 


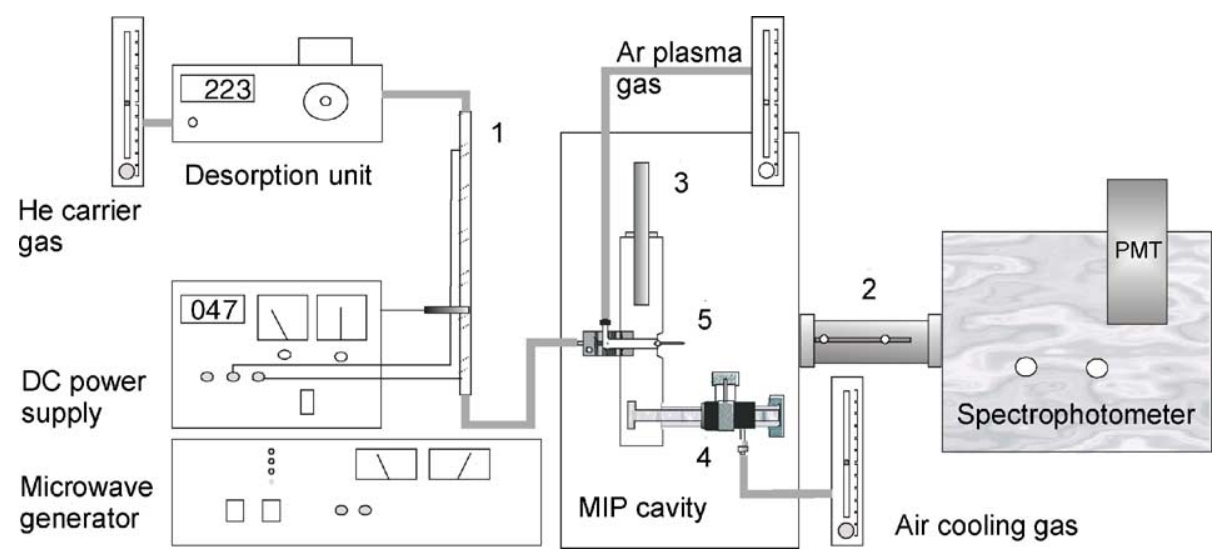

Fig. 1. Instrumental set-up for the SPME-MC-MIP-AES system (1: multicapillary column with resistance wires and J-type thermocouple, 2: focussing tube, 3: fine-tuning stub, 4: microwave antenna, 5: plasma discharge).

of a regulated DC power supply (Dirland D-ADPS-305), modified with a set-point controller (Campini HTX031) for proper temperature control. The J-type thermocouple was placed inside the glass tubing housing the multicapillary column. GC experiments were carried out using an Agilent 5890 Series II GC. The detector was bypassed and carrier gas was fed directly into the MIP discharge. Columns tested were HP-1 $(15 \mathrm{~m} \times 0.53 \mathrm{~mm}$, d.f.: $1.5 \mu \mathrm{m}$, $100 \%$ polydimethylsiloxane), HP-5 $(30 \mathrm{~m} \times 0.25 \mathrm{~mm}$, d.f.: $0.5 \mu \mathrm{m}, 5 \%$ phenylmethylpolysiloxane), HP-wax $(15 \mathrm{~m} \times 0.32 \mathrm{~mm}$, d.f.: $0.25 \mu \mathrm{m}$, crosslinked polyethyleneglycol $)$ and SPB-50 $(30 \mathrm{~m} \times 0.32 \mathrm{~mm}$, d.f.: $0.25 \mu \mathrm{m}, 50 \%$ phenyl-50\% methylpolysiloxane). All transfer lines (total length $40 \mathrm{~cm}$ ) were made by deactivated fused silica tubing (Supelco, Bellefonte, PA, USA, i.d.: $0.25 \mathrm{~mm}$ ).

The microwave generator was an AF GMW 24-303 D (AF Analysetechnik, Tübingen, Germany), operating at a frequency of $2.45 \mathrm{GHz}$ with a tuneable forward power between 30 and $300 \mathrm{~W}$. The reflected power was adjusted to a minimum after igniting the plasma. A $\mathrm{TM}_{010}$ Beenakker type cavity (Model HMW 25-471 N-W, AF Analysetechnik, Tübingen, Germany) was used, provided with ceramic discharge tubes $(60 \mathrm{~mm} \times 4 \mathrm{~mm} \times 2 \mathrm{~mm}$; length, outer/inner diameter) with tangential flow design. The discharge tube was cooled by air, at higher microwave forward powers the cavity was additionally cooled through the inner walls by a stream of water. The system was provided with a home-built three-dimensional movable cavity holding device in order to optimize the plasma position. Horizontal plasma emission was focused to the entrance slit of the detector by the means of an adjustable alignment of two convex lenses (Newport SPX025, UV fused silica, diameter: 1 in., $f=150 \mathrm{~mm}$ ) positioned in a stainless steel tube and attached to the spectrophotometer. The latter had a $300 \mathrm{~mm}$ focal length aspheric mirror Czerny-Turner design, (SpectraPro 300i, Acton Research Corp., MA, USA) a $1200 \mathrm{G} / \mathrm{mm}$ grating and was equipped with a side window UV sensitive photomultiplier tube (1P28 Hamamatsu Photonics, Japan) as detector. Data recording and treatment was done with SpectraSense V4.2.7 software, provided with the instrument. Optimized instrumental parameters for organo-selenium determination are summarized in Table 1. Wavelength calibration and optimization of the position of the focussing lens arrangement was done by the means of an Se EDL lamp, operated at $240 \mathrm{~mA}$ and connected to a Perkin Elmer EDL System 2 power supply.

\subsection{Reagents and standards}

Dimethylselenide and dimethyldiselenide were obtained from Alfa Aesar (Karlsruhe, Germany). Diethylselenide as well as the inorganic selenium species, selenite $\left(\mathrm{Na}_{2} \mathrm{SeO}_{3}\right)$ and selenate $\left(\mathrm{Na}_{2} \mathrm{SeO}_{4}\right)$, were bought from Sigma Aldrich

Table 1

Optimized instrumental parameters for organo-selenium determination using SPME-MC-MIP-AES

\begin{tabular}{|c|c|}
\hline \multicolumn{2}{|c|}{ SPME extraction } \\
\hline Fiber & Carboxen/PDMS $75 \mu \mathrm{m}$ \\
\hline Extraction time & $35 \mathrm{~min}$ \\
\hline Extraction temperature & $25^{\circ} \mathrm{C}$ \\
\hline Stirring & $350 \mathrm{rpm}$ \\
\hline \multicolumn{2}{|c|}{ MC separation } \\
\hline Column type & $\begin{array}{l}25 \mathrm{~cm}, N \approx 1000,40 \mu \mathrm{m} \text { i.d., } \\
\text { OV-17, f: } 0.2 \mu \mathrm{m}\end{array}$ \\
\hline He carrier gas & $38 \mathrm{ml} \mathrm{min}^{-1}$ \\
\hline Desorption temperature & $220^{\circ} \mathrm{C}$ \\
\hline Column temperature & $30^{\circ} \mathrm{C}$ \\
\hline \multicolumn{2}{|c|}{ MIP-AES detection } \\
\hline MIP forward power & $120 \mathrm{~W}$ \\
\hline Reflected power & $18 \mathrm{~W}$ \\
\hline Ar plasma gas & $50 \mathrm{ml} \mathrm{min}^{-1}$ \\
\hline Air cooling gas & $280 \mathrm{ml} \mathrm{min}^{-1}$ \\
\hline Analytical wavelength & $196.0 \mathrm{~nm}$ \\
\hline Entrance/exit slit-width & $10 / 40 \mu \mathrm{m}$ \\
\hline PMT voltage & $700 \mathrm{~V}$ \\
\hline Integration time & $50 \mathrm{~ms}$ \\
\hline Interval time & $100 \mathrm{~m} \mathrm{~s}$ \\
\hline
\end{tabular}


(Madrid, Spain). Stock solutions of the organo-selenium species of $10.000 \mathrm{mg} \mathrm{l}^{-1}$ (expressed as metal) were prepared by appropriate diluting with methanol and stored at $4{ }^{\circ} \mathrm{C}$. Lower concentrated stock solutions $\left(100 \mathrm{mg} \mathrm{l}^{-1}\right)$ were prepared in a $50 \%$ mixture of methanol/water. Aqueous working solutions were prepared daily and stored on ice until use. All fibers investigated were purchased from Supelco (Bellefonte, PA, USA). De-ionized water was obtained from a Millipore (Bedford, MA, USA) ZMFQ 23004 Milli-Q water system. Helium, argon and air (99.99\% purity) were purchased from Carburos Metalicos.

The Agriculture and Trade Council of the Extremadura Autonomous Community Government (Cáceres, Extremadura, Spain) supplied lupine (Lupinus albus) and Indian mustard (B. juncea) seeds. Fresh garlic (Allium sativum) as well as fresh baker yeast (Saccharomyces cerevisiae) samples were bought in a local market.

\subsubsection{Safety note}

DMSe and DMDSe have the following risk notes (R) [34] and safety (S) [35] phrases: R23/25-33-50/53; S20/21-28-45-60-61. The toxicological properties of DEtSe have not been fully investigated, the assigned RS notes are: R23/24/25, S20,24,28,36/37/39,45. All reagents should be handled with caution, high concentrated stock solutions have to be prepared in a flow box, wearing appropriate protection (gloves, laboratory glasses, clothes).

\subsection{Analytical procedure}

The analytical procedure for sampling using SPME is fairly simple. Five milliliters of the sample were placed together with a $6 \mathrm{~mm}$ stirrer in a $10 \mathrm{ml}$ headspace vial, the latter was closed with an aluminum seal and a Teflon faced butyl septum. The vial was placed onto a magnetic stirrer. A fiber, placed in a fiber assembly holder (Supelco), was used for passing the fiber through the septum during sampling. Loaded fibers were transferred to the desorption unit for measurement directly after sampling.

For garlic samples, several batches containing from 50 to $500 \mathrm{mg}$ of fresh cut garlic were prepared, particle size was about $1 \mathrm{~mm}$ and all parts of the bulb were used. Headspace extraction was carried out immediately after sample preparation. Yeast samples were prepared by dispersing $300 \mathrm{mg}$ of fresh yeast in $5 \mathrm{ml}$ of $\mathrm{Se}(\mathrm{IV})$ stock solution, at a concentration level of $1-4 \mathrm{mg} \mathrm{l}^{-1}$. The mixture was stirred at room temperature for $48 \mathrm{~h}$ prior to sampling. Leave and root samples from lupine and Indian mustard were harvested periodically after growing the plants, following the protocol described below. About $250-500 \mathrm{mg}$ of the samples were crushed using a glass bar and placed into the vial for immediate sampling.

\subsubsection{Lupine and Indian mustard growing conditions}

Prior to germination, the seeds were disinfected with diluted bleach $(10 \%, \mathrm{v} / \mathrm{v})$ for $10 \mathrm{~min}$ and rinsed with distilled water. The sterilized seeds were germinated on sand moistened with de-ionized water. After germination of the seeds, the sand was moistened with 0.02 strength Hoagland's nutrient solution [36]. The seedlings were transferred 5-7 days after germination to 1.51 vessels, containing a 0.1 strength Hoagland's nutrient solution, where they were grown for 2 weeks under daylight conditions. Air was continuously bubbled into the nutrient solution which was renewed every 3 days. $\mathrm{Na}_{2} \mathrm{SeO}_{3}$ and $\mathrm{Na}_{2} \mathrm{SeO}_{4}$ were independently supplied into the medium at a concentration level of 1 and $5 \mathrm{mg}^{-1}$. Two pots were used per selenium source and concentration, each containing 12 plants. Each pot was covered by a $22 \mathrm{~cm} \times 22 \mathrm{~cm} \times 20 \mathrm{~cm}$ transparent methacrylate box, equipped in the upper part with a removable septum (Termogreen LB-2, Supelco), placed in a holding device, in order to allow periodically SPME sampling in headspace above the living plant. A control pot was also used as a blank with no selenium spike.

\section{Results and discussion}

As it has been mentioned above, analytical variables must be optimized to obtain reliable and confidence results. Due to the large number of variables involved in method optimization, they were grouped according to the analysis steps: extraction on the SPME fiber, injection in the desorption device, separation of peaks and detection conditions. First, conditions related to the detection (microwave power, argon and airflow rates) were evaluated and optimized by means of a factorial design and evaluation of the obtained results by analysis of variance (ANOVA). Then, different stationary phases for capillary columns (HP-1, HP-5, SPB-50 and HP-wax) were evaluated in order to properly separate selenium species. The appropriate one was used to optimize separation conditions for multicapillary gas chromatography (temperature and helium column head pressure). The behavior of the MC column (OV-1701) was compared under similar operating conditions to the one of a conventional GC column (SPB-50). Finally, a design of experiments was used to optimize the injection temperature in the fiber desorption unit and extraction conditions with SPME fibers (temperature and time).

\subsection{Optimization of MIP-AES detection}

The stability and optimum response of a microwave induced plasma highly depends on the flow rates of the gases used: argon to create and to maintain the plasma and air to enhance the combustion of organic compounds, to improve the stability of the baseline and to enhance the lifetime the discharge tubes by cooling. The response is also highly dependent on the microwave power submitted to plasma. Previous to the optimization procedure, antenna position and fine-tuning for proper coupling of the microwave energy within the cavity were optimized to obtain the maximum 
Table 2

Factor and levels considered in the full factorial design to check the influence of the microwave power $(P)$, make-up argon flow rate $\left(F_{\mathrm{Ar}}\right)$ and air flow rate $\left(F_{\mathrm{A}}\right)$ on the response

\begin{tabular}{lcll}
\hline Variable & Low $(-)$ & Central $(0)$ & High $(+)$ \\
\hline$P(\mathrm{~W})$ & 70 & 110 & 150 \\
$F_{\mathrm{Ar}}\left(\mathrm{ml} \mathrm{min}^{-1}\right)$ & 50 & 100 & 150 \\
$F_{\mathrm{A}}\left(\mathrm{ml} \mathrm{min}^{-1}\right)$ & 0 & 140 & 280 \\
\hline
\end{tabular}

signal/noise ratio. A full factorial design with three factors at two levels and four replicates of the central point $\left(2^{n}+1\right)$ [37], involving 12 experiments in random order was initially applied to establish the influence or lack of influence of each of the first set of variables (microwave power, argon and air flow rates).

In each experiment a mixture of $50 \mathrm{ng} \mathrm{ml}^{-1}$ of the each selenium species tested was analyzed as described in Section 2. The factors and levels considered are shown in Table 2. Results obtained for the peak area corresponding to dimethyldiselenium (similar results are obtained for each of the dimethylselenium and diethylselenium peak areas) in each experiment are summarized in Table 3.

The standard deviation of the central point allowed to calculate, by means of the YATES algorithm [37], the $F$ factor of each variable or combination of variables, which are also included in Table 3. Analysis of variance (ANOVA) of the results shows that all variables, apart from air flow, have a direct statistically significant effect on the DMDSe signal $(F>5.32$ at a $95 \%$ confidence level) [38]. Air flow acts basically for discharge tube cooling, which allows to apply higher MIP forward power. It avoids as well changes of the discharge tube temperature during one analysis run. A direct effect on sensibility could be expected by stabilising the cone shape of the discharge and by avoiding flickering of the exhaust fume, which presents advantages when the light is focused to the entrance slit of the monocromator. The fact that air flow does not directly influence the sensibility (see Table 3) could be interpreted as another indication for the fair robustness of the developed method. Even though a

Table 3

Design matrix, response values, main and $F$ factors obtained from the factorial design developed to investigate the plasma conditions in the MIP-AES detector ${ }^{\mathrm{a}}$

\begin{tabular}{llllllc}
\hline Combinations & Levels & & $\begin{array}{l}\text { DMDSe peak } \\
\text { area (a.u.) }\end{array}$ & Main factor & $F$ \\
\hline$(1)$ & - & - & - & 8545902 & & \\
$P$ & + & - & - & 11002385 & 3128093.88 & 2547 \\
$F_{\mathrm{Ar}}$ & - & + & - & 4981448 & -3815402.13 & 3789 \\
$P F_{\mathrm{Ar}}$ & + & + & - & 8922655 & 325770.375 & 27.6 \\
$F_{\mathrm{A}}$ & - & - & + & 8041935 & 41393.625 & 0.44 \\
$P F_{\mathrm{A}}$ & + & - & + & 12383073 & 241359.125 & 15.16 \\
$F_{\mathrm{Ar}} F_{\mathrm{A}}$ & - & + & + & 4517018 & -681199.875 & 120.8 \\
$P F_{\mathrm{Ar}} F_{\mathrm{A}}$ & + & + & + & 7795506 & -132358.625 & 4.56 \\
\hline
\end{tabular}

${ }^{\text {a }}$ Factors in italic were found to be statistically significant after ANOVA of the results $(F>5.32$ at a $95 \%$ confidence level).
Table 4

Variable and levels for the central composite design

\begin{tabular}{lrrrrr}
\hline Variables & \multicolumn{2}{l}{ Levels } & & \\
\cline { 2 - 6 } & $-\alpha$ & - & 0 & + & $+\alpha$ \\
\hline Microwave power, $P(\mathrm{~W})$ & 70 & 90 & 110 & 130 & 150 \\
Argon flow rate, $F_{\mathrm{Ar}}\left(\mathrm{ml} \mathrm{min}^{-1}\right)$ & 50 & 60 & 75 & 90 & 100 \\
Air flow rate, $F_{\mathrm{A}}\left(\mathrm{ml} \mathrm{min}^{-1}\right)$ & 0 & 30 & 140 & 250 & 280
\end{tabular}

direct effect of air flow on the analyte response could not be established, the combination with other parameters had a statistically significant effect, therefore it was necessary to also optimize this variable.

Posterior maximization of peak response was carried by means of central composite design. The central composite design consisted of the points of a factorial design $\left(2^{n}\right)$ augmented with six points located at $-\alpha$ and $+\alpha$ from the center in a star design (Table 4).

To define the response surface, and thus, to obtain optimal values of the variables, results obtained are fitted to a general polynomial equation (Eq. (1)) where $\beta$ are the adjustable parameters.

$$
\begin{aligned}
Y= & \beta_{0}+\beta_{1} P+\beta_{2} F_{\mathrm{Ar}}+\beta_{3} F_{\mathrm{A}}+\beta_{11} P^{2}+\beta_{22} F_{\mathrm{Ar}}^{2} \\
& +\beta_{33} F_{\mathrm{A}}^{2}+\beta_{12} P F_{\mathrm{Ar}}+\beta_{13} P F_{\mathrm{A}}+\beta_{23} F_{\mathrm{Ar}} F_{\mathrm{A}} \\
& +\beta_{123} P F_{\mathrm{Ar}} F_{\mathrm{A}}
\end{aligned}
$$

Fit of data to Eq. (1) was performed using the multivariate non-linear regression analysis program NLREG [39], and those parameters $\beta$ with a statistical probability to be zero greater than $10 \%$ were sequentially eliminated from the model. The model finally selected (Eq. (2)) is able to explain $98.45 \%$ of the total variance of data.

$$
\begin{aligned}
Y= & 2.38 \times 10^{6}+2.54 \times 10^{5} P+9.54 \times 10^{4} F_{\mathrm{Ar}}-5.51 \\
& \times 10^{4} F_{\mathrm{A}}-1.2 \times 10^{3} P^{2}-383.7 F_{\mathrm{Ar}}^{2}+84.9 F_{\mathrm{A}}^{2} \\
& +526.8 P F_{\mathrm{Ar}}+392.8 P F_{\mathrm{A}}+439.5 F_{\mathrm{Ar}} F_{\mathrm{A}} \\
& -4.01 P F_{\mathrm{A}} F_{\mathrm{Ar}}
\end{aligned}
$$

The response surface predicted by the model can be visualized (Fig. 2) if one of the three variables is maintained constant. The variable values that maximize the response obtained can be calculated mathematically. Results are $120 \mathrm{~W}$ for the microwave forward power, $50 \mathrm{ml} \mathrm{min}^{-1}$ for the make-up argon flow rate $\left(F_{\mathrm{Ar}}\right)$ and $280 \mathrm{ml} \mathrm{min}^{-1}$ as air flow rate $\left(F_{\mathrm{A}}\right)$ on the plasma conditions. These values were considered as optimal plasma conditions for selenium speciation.

\subsection{GC versus multicapillary columns}

Different stationary phases for GC columns of different polarity (HP-1, HP-5 and HP-wax) were evaluated for the correct separation of selenium species, and also to obtain maximum peak area and optimum peak shape. 


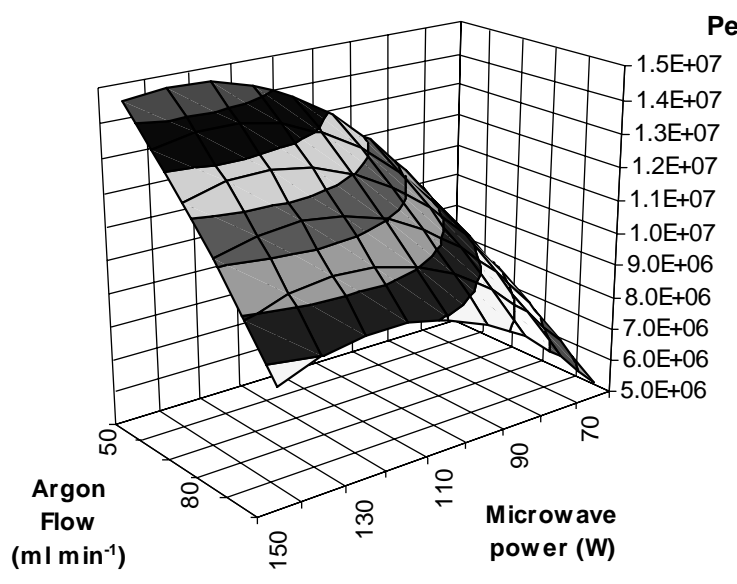

Fig. 2. Response surface estimated from central composite design for DMDSe MIP-AES detection optimization maintaining the air flow constant at optimum value $\left(F_{\mathrm{A}}=280 \mathrm{ml} \mathrm{min}^{-1}\right)$.

Organo-selenium species are almost non-polar compounds and, consequently, non-polar separation phases such as HP-1 (100\% dimethylpolysiloxane) should be more efficient for a correct separation. But after comparison of the peak areas and retention times obtained with the three different columns tested (Fig. 3), it was established that an intermediate polarity column (HP-5) provides more adequate separation of the species investigated peaks.

Consequently, a multicapillary column with a mid-polarity stationary phase (50\% phenyl-methylpolysiloxane) was used for further optimization. Helium carrier gas flow and column temperature during separation were varied in order to obtain baseline resolved analyte peaks, chromatographic peak shapes, fast separation and low noise level. Analyte response was evaluated as area. Optimum conditions were found to be a carrier gas flow of $38 \mathrm{ml} \mathrm{min}^{-1}$ and a column temperature of $30^{\circ} \mathrm{C}$. Under these conditions a complete chromatogram of the three analytes could be achieved in approximately $2 \mathrm{~min}$. Fig. 4 highlights the superior performance of the MC column compared with a conventional GC column of similar characteristics. The latter causes the duplication of the time needed for one analysis run, furthermore the peak areas obtained with the multicapillary column are significantly higher.

The low temperature applied for separation has the advantage that it allows a very comfortable design for the instrumental set-up of the SPME-MC-MIP-AES system, as there is no need for the use of an additional gas chromatographic oven. This simplifies, furthermore, the hyphenation between this separation technique and alternative detectors, such as ICP or AFS.

\subsection{Optimization of the SPME extraction and desorption process}

In a previous work, several commercially available fibers, covering the range of available properties in terms of extraction mechanism, film thickness and polarity, were evaluated for the simultaneous determination of DMSe and DMDSe [33]. A Carboxen ${ }^{\mathrm{TM}} / \mathrm{PDMS}$, partially crosslinked $75 \mu \mathrm{m}$ coated fiber was found to be optimal. Consequently, this fiber was used in the ongoing experimental work.

Just as in the previous optimization of plasma conditions, a full factorial design was used to evaluate a second group of variables, related with SPME extraction and desorption of the analyte into the gas chromatographic system. These variables were extraction temperature $\left(T_{\mathrm{e}}\right)$, extraction time $(t)$ and the temperature of the injection port $\left(T_{\mathrm{d}}\right)$. Analyte response was evaluated as peak area. The levels considered for each factor are shown in Table 5 and the results obtained for each point of the experimental design are summarized in Table 6. ANOVA of the results, calculated also by means of the YATES algorithm (Table 6), confirmed that all the three variables investigated show a statistically significant influence on analyte response $(F>5.32$ at a $95 \%$ confidence

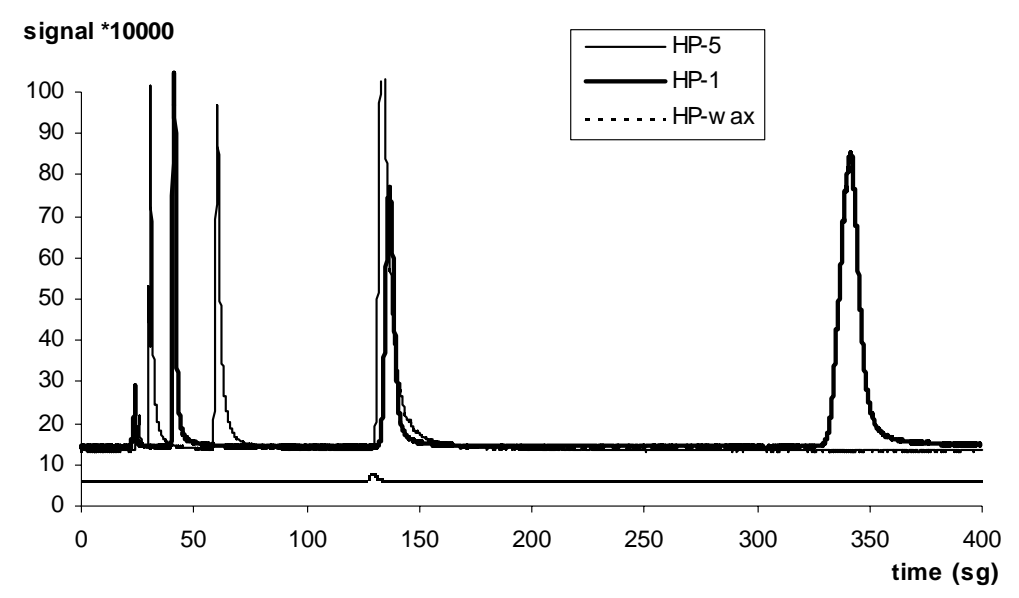

Fig. 3. Gas chromatograms for the DMSe, DEtSe and DMDSe using HP-1, HP-5 and HP-wax columns [HP-wax signal offset (-10) for better view]. $\mathrm{He}$ column flow $15 \mathrm{ml} \mathrm{min}^{-1}$ for $\mathrm{HP}-1,6.90 \mathrm{ml} \mathrm{min}^{-1}$ for HP-wax and $8.65 \mathrm{ml} \mathrm{min}^{-1}$ for HP-5, and temperature column $30^{\circ} \mathrm{C}$. SPME extraction of $100 \mathrm{ng} \mathrm{ml}^{-1}$ of each species and MIP-AES detection. 


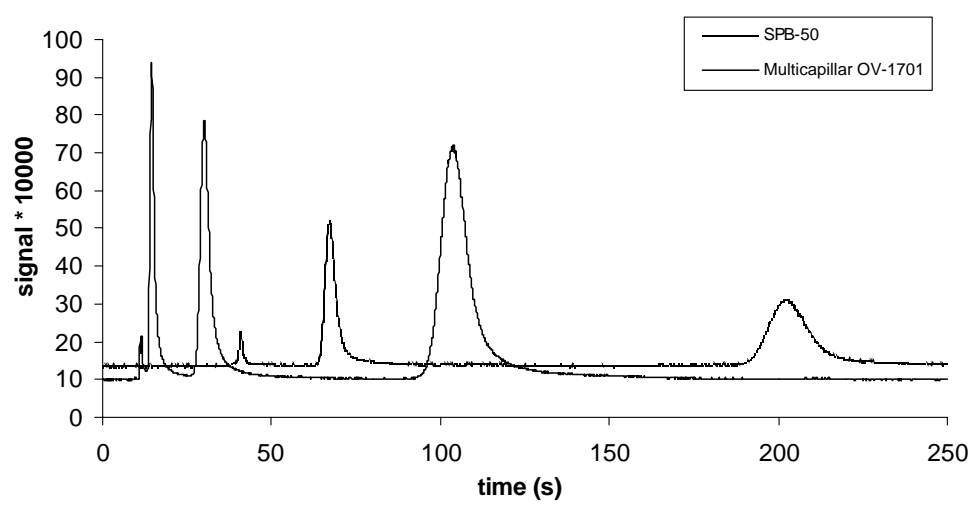

Fig. 4. Chromatograms for the DMSe, DEtSe and DMDSe selenium compounds using SPB-50 and multicapillary OV-1701 gas columns. He column flow $38 \mathrm{ml} \mathrm{min}^{-1}$ for MC OV-1701 and $9.90 \mathrm{ml} \mathrm{min}^{-1}$ for SPB-50 and temperature column of $30^{\circ} \mathrm{C}$. SPME extraction of $100 \mathrm{ppb}$ of each specie and MIP-AES detection.

level). Consequently, all of them were considered in the optimization process.

This maximization of peak response was carried by means of central composite design. Results obtained in this experimental design are fitted to a similar general polynomial equation to define response surface, obtaining in this case the Eq. (3), which is able to explain $97.7 \%$ of the total variance of data.

$$
\begin{aligned}
Y= & -1.5 \times 10^{6}+9.82 \times 10^{3} T_{\mathrm{e}}+6.81 \times 10^{3} t+1.78 \\
& \times 10^{4} T_{\mathrm{d}}-102.2 T_{\mathrm{e}}^{2}+87 t^{2}-40.8 T_{\mathrm{d}}^{2}-163.85 T_{\mathrm{e}} t \\
& +0.22 T_{\mathrm{e}} T_{\mathrm{d}}-26.1 t T_{\mathrm{d}}-0.25 T_{\mathrm{e}} t T_{\mathrm{d}}
\end{aligned}
$$

Table 5

Factor and levels considered in the full factorial design to check the influence of temperature of extraction $\left(T_{\mathrm{e}}\right)$, time of extraction $(t)$ and temperature of the injection port $\left(T_{\mathrm{d}}\right)$ on the response

\begin{tabular}{lccc}
\hline Variable & Low $(-)$ & Central $(0)$ & High $(+)$ \\
\hline$T_{\mathrm{e}}\left({ }^{\circ} \mathrm{C}\right)$ & 20 & 45 & 70 \\
$t(\min )$ & 5 & 32.5 & 60 \\
$T_{\mathrm{d}}\left({ }^{\circ} \mathrm{C}\right)$ & 140 & 190 & 240 \\
\hline
\end{tabular}

Table 6

Design matrix, response values, main and $F$ factors obtained from the factorial design developed to evaluate extraction and desoption conditions during SPME extraction ${ }^{\mathrm{a}}$

\begin{tabular}{llllrll}
\hline Combinations & Levels & & $\begin{array}{l}\text { DMDSe peak } \\
\text { area (a.u.) }\end{array}$ & Main factor & $F$ \\
\hline$(1)$ & - & - & - & 342803 & & \\
$T_{\mathrm{e}}$ & + & - & - & 313723 & -340500.75 & 2090.7 \\
$t$ & - & + & - & 578270 & -142065.25 & 363.9 \\
$T_{\mathrm{e}} t$ & + & + & - & 664463 & 158414.75 & 452.5 \\
$T_{\mathrm{d}}$ & - & - & + & 21067 & -261646.25 & 1234.5 \\
$T_{\mathrm{e}} T_{\mathrm{d}}$ & + & - & + & 535834 & -47359.25 & 40.4 \\
$t T_{\mathrm{d}}$ & - & + & + & 668158 & -113470.75 & 232.1 \\
$T_{\mathrm{e}} t T_{\mathrm{d}}$ & + & + & + & 21067 & 2415.25 & 0.1 \\
\hline
\end{tabular}

${ }^{\text {a }}$ Factors in italic were found to be statistically significant after ANOVA of the results $(F>5.32$ at a $95 \%$ confidence level $)$.
The response surface predicted by the model is shown in Fig. 5, maintaining the extraction temperature constant $\left(T_{\mathrm{e}}=45^{\circ} \mathrm{C}\right)$. Mathematically, the conditions to achieve optimum separation and sensibility in the analysis of selenium species were $T_{\mathrm{e}}=45^{\circ} \mathrm{C}, t=37.5 \mathrm{~min}$ and $T_{\mathrm{d}}=240^{\circ} \mathrm{C}$. Results of optimization obtained for the earlier eluting species (DMSe and DEtSe) are slightly different, showing (Fig. 6) identical optimum value for the desoption temperature $\left(T_{\mathrm{d}}=240^{\circ} \mathrm{C}\right)$, but the response signal decreased significantly when temperature and extraction time are increased. This effect could be attributed to water absorbed on the fiber, which causes interferences in the chromatograms overlapping with the signal of these selenium species. Therefore a lower temperature $\left(25^{\circ} \mathrm{C}\right)$ was chosen as compromise for the simultaneous detection of the three species.

\subsection{Analytical characteristics}

\subsubsection{Figures of merit}

The analysis of standard aqueous mixtures of dimethyl-, diethyl- and dimethyldiselenium by the procedure described

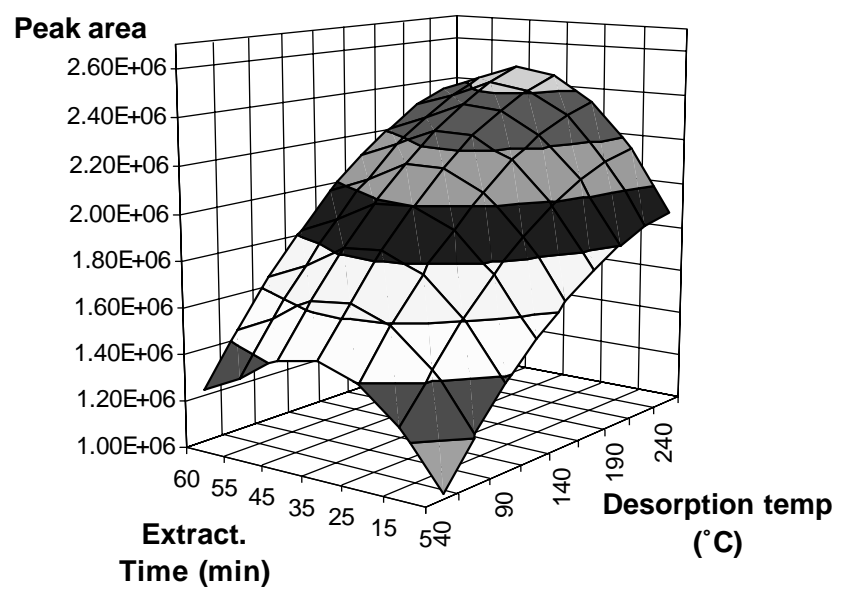

Fig. 5. Response surface estimated from central composite design for DMDSe SPME extraction optimization maintaining the extraction temperature constant at optimum value $\left(T_{\mathrm{e}}=45^{\circ} \mathrm{C}\right)$. 


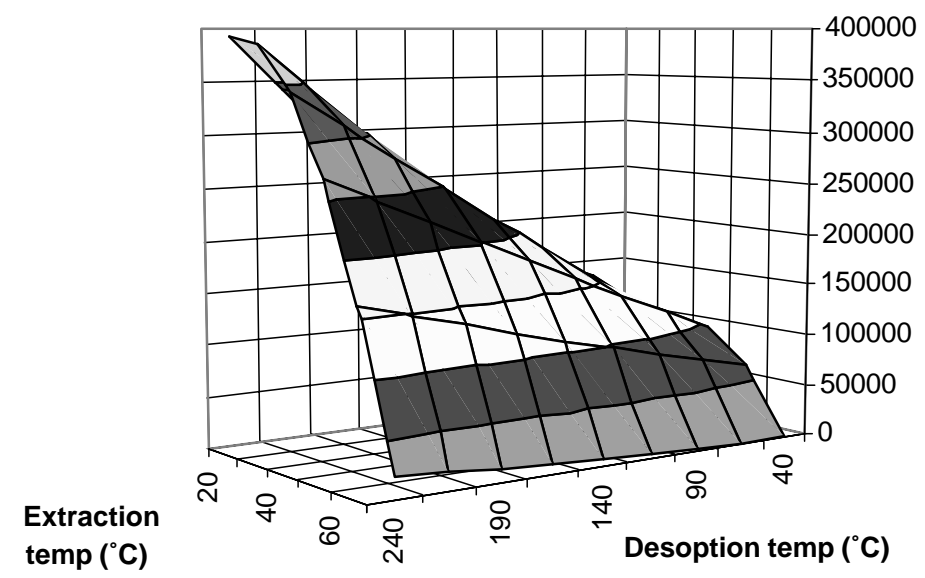

Fig. 6. Response surface estimated from central composite design for DMSe SPME extraction optimization maintaining the extraction time constant at optimum value $(t=37.5 \mathrm{~min})$.

in Section 2 and using the best conditions proposed in this work, produced linear calibration curves of high quality $\left(R^{2}>0.991,>0.975\right.$ and $>0.967$ for DMSe, DEtSe and DMDSe, respectively) within the concentration range investigated (DL to $100 \mathrm{ng} \mathrm{ml}^{-1}$ ).

Detection limits, defined as blank signal plus three times the signal-to-noise ratio, were determined for a sample of $5 \mathrm{ml}$ of synthetic samples: $0.57 \pm 0.04 \mathrm{ng} \mathrm{ml}^{-1}$ for DMSe, $0.47 \pm 0.04 \mathrm{ng} \mathrm{ml}^{-1}$ for DEtSe and $0.19 \pm 0.02 \mathrm{ng} \mathrm{ml}^{-1}$ for DMDSe. An absolute detection limit can be estimated for the SPME extraction technique repeating the extraction for the same sample until the obtained analyte response becomes negligible. With a known absolute analyte concentration the theoretical total response should be the sum of the areas obtained experimentally. In the present case $5 \mathrm{ml}$ of a $25 \mathrm{ng} \mathrm{ml}^{-1}$ mixed standard solution was exposed to 15 subsequent extractions, the decay in analyte response (expressed as area) was fitted to an exponential regression and extrapolated to a value coinciding with the typical noise level of the system. Using the $3 \sigma$-value absolute detection limits were calculated to be $0.26,1.35$ and $0.36 \mathrm{ng}$ for DMSe, DEtSe and DMDSe, respectively.

The precision of the analysis by SPME-MC-MIP-AES of five different samples of $15 \mathrm{ng} \mathrm{ml}^{-1}$ for each species, measured during 1 day and using different fibers of similar characteristics was 7.76\% for DMSe, 7.89\% for DEtSe and $7.06 \%$ for DMDSe, expressed in terms of relative standard deviation. Reproducibility for retention times of the species was $2.08,3.85$ and $4.36 \%$ for DMSe, DEtSe and DMDSe, respectively.

\subsubsection{Application to real samples}

The analytical method developed was directly applied for determination of organo-selenium in plants (Indian mustard, garlic and lupine) and in yeast. Sampling time was $45 \mathrm{~min}$ in the case of crushed plant samples and yeast and up to $24 \mathrm{~h}$ for headspace measurements above the living plants. As an example, Fig. 7 shows the chromatograms obtained for Indian mustard and yeast, both enriched with Se(IV). Species identification was carried out by comparison of retention times and spike experiments (Table 7).

All in all, nine different volatile organo-selenium species could be distinguished in the investigated samples. Three of them (DMSe, DEtSe and DMDSe) could be directly identified, as the corresponding standards are commercially available. Another specie, eluting between DEtSe and DMDSe, was preliminarily identified as a mixed compound (DMSe-S), containing sulfur as well as selenium, by monitoring the sulphur emission line at $190.6 \mathrm{~nm}$ and by ICP-MS measurements at $\mathrm{m} / \mathrm{z}$ 34. This observation is in agreement with data reported earlier [28] for a similar kind of samples.

At least a part of the remaining species are to some extend likely to be sulphur-containing analogues of the known species, DEtSe-S for instance, but current data obtained

Table 7

Selenium species encountered in biological samples

\begin{tabular}{|c|c|c|c|}
\hline Label & $\begin{array}{l}\text { Retention } \\
\text { time }(\mathrm{s})\end{array}$ & $\begin{array}{l}\text { Selenium } \\
\text { specie }\end{array}$ & Found in \\
\hline 1 & 17 & DMSe & $\begin{array}{l}\text { Yeast, mustard }(\mathrm{hs})^{\mathrm{a}} \text {, lupine } \\
(\mathrm{cr})^{\mathrm{b}} \text {, garlic }\end{array}$ \\
\hline 2 & 26 & Not identified & Lupine (cr), garlic \\
\hline 3 & 38 & DEtSe & Yeast, mustard (hs), garlic \\
\hline 4 & 50 & Not identified & Yeast, lupine (cr) \\
\hline 5 & 70 & $\mathrm{DMSe}-\mathrm{S}^{\mathrm{c}}$ & Yeast, mustard (hs), garlic \\
\hline 6 & 96 & Not identified & Lupine (cr), mustard (cr) \\
\hline 7 & 117 & DMDSe & $\begin{array}{l}\text { Yeast, lupine (hs), mustard } \\
\text { (hs), }\end{array}$ \\
\hline 8 & 150 & Not identified & Mustard (cr), garlic \\
\hline 9 & 280 & Not identified & Yeast, garlic \\
\hline
\end{tabular}

${ }^{a}$ Headspace above living sample.

${ }^{\mathrm{b}}$ Headspace above crushed sample.

${ }^{c}$ Identification by MIP-AES (190.6 nm) and ICP-MS $\mathrm{m} / \mathrm{z}$ 34, preliminary. 

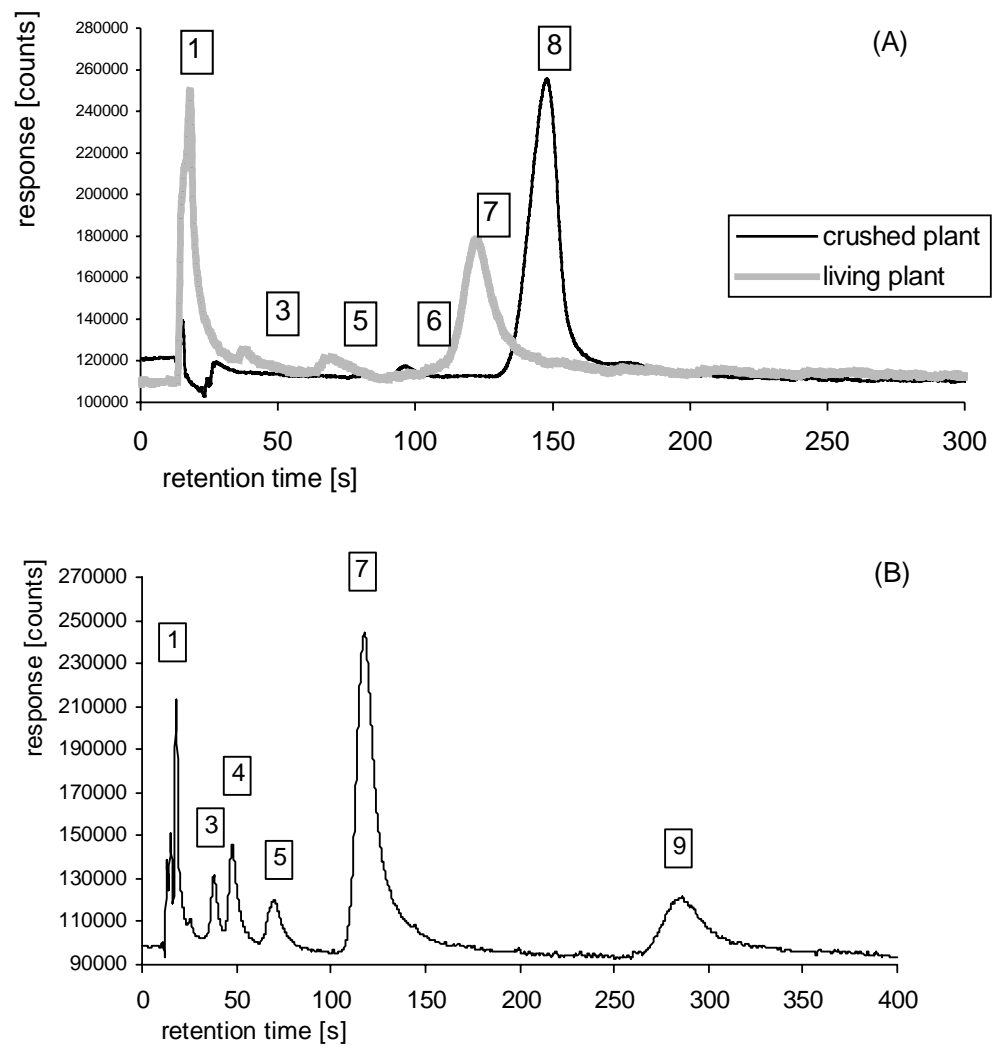

Fig. 7. MC-MIP-AES chromatograms obtained after SPME extractions using optimized working conditions for (a) Indian mustard, for living and crushed sample and (b) yeast.

when monitoring sulphur by MIP-AES or ICP-MS does not allow us to confirm that observation by now. More experimental work and possibly the use of an alternative analytical technique, such as ESI-MS, will be necessary to clarify this point.

Quantification of species can only be carried out for identified species whose standards are available. Furthermore, due to the nature of SPME sampling technique, proper quantification is only possible when samples are measured in a vial (in this particular case yeast and crushed plant samples), where it is possible to apply comparative quantification methods such as external calibration or standard addition. When applying standard addition some problems arise due to important matrix effect, which makes quantification difficult. The results obtained have been reckoned out from the comparison of the signal obtained with external calibration, with the corresponding drawbacks. A semi-quantification of the unidentified species is possible comparing the signal obtained with those of identified species.

The chromatograms obtained show that the organoselenium species detected in the measurements done in the headspace of growing plants (lupine and Indian mustard) are different to those detected in the headspace of the same, but crushed plant. This proves that there is no direct metabolism from inorganic selenium to the organo-selenium compounds finally released by the plant. In the crushed
Indian mustard sample (Fig. 7A), the only species detected were two unidentified ones (labelled numbers 6 and 8). The headspace sampling in the growing plant revealed DMSe, DEtSe, DMDSe plus an initially unidentified specie, that later was assigned to be DMSe-S.

For the lupine samples a similar behavior was verified. In the crushed sample DMSe was additionally detected, together with three non-identified species of selenium, while by headspace sampling above living plants only DMDSe could be detected (Table 7). The amount of selenium incorporated by this plant seems to be significantly lower than for Indian mustard. No difference in selenium species distribution could be observed depending on the inorganic selenium species used for the enrichment process, but $\mathrm{Se}(\mathrm{VI})$ was found to be less bioavailable than Se(IV).

The richest variety of selenium species was observed in yeast samples (Fig. 7B). Six selenium species were detected, three identified (DMSe, DEtSe and DMDSe) and three unknown species (one of them, labelled as number 5, was the later identified as DMSe-S). Yeast metabolizes inorganic selenium extraordinarily fast, $12 \mathrm{~h}$ after addition of inorganic selenium the dispersion had already changed the colour from light brown to reddish and sampling in headspace resulted in the detection of all the above-mentioned species. Found concentrations for the known species were approximately $8-10 \mathrm{ng} \mathrm{ml}^{-1}$ for DMSe and DMDSe and of $2 \mathrm{ng} \mathrm{ml}^{-1}$ for DEtSe. The concentration of the unidentified species is 
probably at sub-ppb level, presuming that sensitivity for those species is comparable to that obtained for the known ones. Species labelled as number 9 shows a peak area similar to that obtained for DMDSe. Garlic shows a selenium distribution similar to that of enriched yeast samples, detecting also six selenium species, but only two of them definitively identified (Table 7). Although the variations in the number of selenium species detected and their concentration was high in between different garlic samples, the results are in agreement with earlier observations by Block et al. [40], who was able to identify seven volatile selenium species in garlic samples by GC-AED and GC-MS.

\section{Conclusions}

With the coupling of SPME-MC-MIP-AES, a novel, simple and economic method for organo-selenium speciation is presented. The characteristics of the method, in terms of sensitivity and reliability are at the frontiers of State of the Art in its field in Analytical Chemistry and can compete with, or even surpass, highly sophisticated instrumentation such as GC-ICP-MS. Detection limits obtained were 0.57, 0.47 and $0.19 \mathrm{ng} \mathrm{ml}^{-1}$ for DMSe, DEtSe and DMDSe, respectively. The selenium species detected in plants are certainly different from the ones released by them, most of the former could not be identified whilst the primary species released are DMSe and DMDSe. Indian mustard and garlic are the plants with the highest organo-selenium concentration. Yeast is able to metabolize inorganic selenium and to release organo-selenium species in a very short period of time. There is still a lack of pure compounds and reference materials for organo-selenium species, allowing unequivocal species identification and improved method validation.

As the separation in the multicapillary can be carried out at reduced temperature, there is no need for an additional GC oven, which makes it even more easy to hyphenate the system with other detection systems, such as AFS, when needed. The system should be suitable for the determination of other organo-metal compounds, eventually after derivatization. The chemometric approach used for method optimization allows the characterization of interdependence of different variables as well as the reduction of the number of experiments necessary for successful method optimization. Further investigation will be focussed on the identification of the unknown selenium species and on application of the proposed method on speciation analysis of other organo-metal compounds.

\section{Acknowledgements}

The authors want to thank the Spanish Government for financial support of this study, through the projects ASESORA (contract No. PB 98-076) and J. Sanz Landaluze is grateful to the Basque Government for his post-doctoral fellowship.

\section{References}

[1] E. Merian, in: E. Merian, R. Frei, W. Härdi, C. Schlatter (Eds.), Carcinogenic and Mutagenic Compounds, Gordon and Breach, London, 1985, p. 25.

[2] J.O. Nriagu, J.M. Pacyna, Nature 333 (1988) 134.

[3] Toxic Release Inventory, 1999. http://www.epa.gov/tri/tridata/tri99/ pdr/appendixa.pdf.

[4] P.J. Craig, in: P.J. Craig (Ed.), Organometallic Compounds in the Environment, Longman, Harlow, 1986, p. 30

[5] L. Fishbein, in: E. Merian (Ed.), Metals and their Compounds in the Environment Occurrence, Analysis and Biological Relevance, VCH, Weinheim, 1991, p. 1153.

[6] L.W. Newland, in: Handbook of Environmental Chemistry, vol. 3B, 1982, p. 45.

[7] H.E. Ganther, O.A. Levander, C.A. Baumann, J. Nutr. 88 (1966) 55.

[8] D. Tanzer, K. Heuman, Int. J. Environ. Anal. Chem. 48 (1992) 17.

[9] C. Cámara, M.G. Cobo, M.A Palacios, R. Muñoz, O.F.X. Donard, in: P. Quevauviller, E.A. Maier, B. Griepink (Eds.), Quality Assurance for Environmental Analysis, Elsevier, Amsterdam, 1995, p. 235

[10] N. Terry, A.M. Zayed, M.P. de Souza, A.S. Tarun, Annu. Rev. Plant Physiol. Plant Mol. Biol. 51 (2000) 401.

[11] G.S. Bañuelos, J. Environ. Qual. 31 (2002) 1802.

[12] D.E. Salt, R.D. Smith, I. Raskin, Annu. Rev. Plant Physiol. Plant Mol. Biol. 49 (1998) 643.

[13] U. Karlson, W.T. Frankenberger, Soil Sci. Soc. Am. J. 52 (1988) 678

[14] S. Jiang, H. Robberecht, F.C. Adams, Appl. Organomet. Chem. 3 (1999) 111.

[15] M.B. Gruntianag, R. Lobinski, F.C. Adams, J. Anal. Atom. Spectrom. 10 (1995) 111.

[16] X.J. Cai, E. Block, P.C. Uden, X. Zhang, B.D. Quimby, J.J. Sulivan, J. Agric. Food Chem. 43 (1995) 1754.

[17] C.L. Arthur, J. Pawliszyn, Anal. Chem. 62 (1990) 2145.

[18] B. Zygmunt, A. Jastrzebska, J. Namiesnik, Crit. Rev. Anal. Chem. 31 (2001) 1.

[19] R. Payne, A.E. Puchalski, J. Labows, Food Sci. 115 (2002) 277.

[20] S. Ulrich, J. Chromatogr. A 902 (2000) 167.

[21] J.C.R. Demyttenaere, M.D. Herrera, N. De Kimpe, Phytochemistry 55 (2000) 363.

[22] D.J. Tranthim-Fryer, R.C. Hansson, K.W. Norman, J. Forensic Sci. 64 (2001) 943.

[23] Z. Mester, R. Sturgeon, J. Pawliszyn, Spectrochim. Acta B 56 (2001) 233

[24] M. Guidotti, J. AOAC Int. 83 (2000) 1082.

[25] M. Guidotti, G. Ravaioli, M. Vitali, J. High Resolut. Chromatogr. 22 (1999) 414.

[26] A.P. Vonderheide, M. Montes-Bayon, J.A. Caruso, Analyst 127 (2002) 49.

[27] S.L. Chong, D.W. James, D. Hayes, B.W. Wilhite, A. Malik, Anal. Chem. 69 (1997) 3889.

[28] J. Mejia, M. Montes-Bayón, D.L. LeDuc, N. Terry, J.A. Caruso, Anal. Chem. 74 (2002) 5837.

[29] S.N. Deming, S.L. Morgan, Experimental Design: A Chemometrical Approach, Elsevier, Amsterdam, 1993.

[30] L. Davies, Efficiency in Research, Development and Production: The Statistical Design and Analysis of Chemical Experiments, Royal Society of Chemistry, Cambridge, 1993.

[31] R.K. Skogerboe, G.N. Coleman, Anal. Chem. A 48 (1976) 611.

[32] E.I. Brooks, K.J. Timmins, Analyst 110 (1985) 557.

[33] C. Dietz, T. Pérez, Y. Madrid, C. Cámara, J. Anal. Atom. Spectrom. 18 (2003) 477. 
[34] Council Directive 2001/59/EC of 6.08.2001 (28th technical adaptation), Official Journal L 225 (2001) 86.

[35] Council Directive 2001/59/EC of 6.08.2001 (28th technical adaptation), Official Journal L 225 (2001) 124

[36] D.R. Hoagland, D.I. Arnon, Calif. Agric. Exp. Stat. Circ. 347 (1950) 1.

[37] T.B. Barker, Quality by Experimental Design, 2nd ed., Marcel Dekker, New York, 1994.
[38] J.C. Miller, J.N. Miller, Statistics for Analytical Chemistry, 2nd ed., Ellis Horwood, London, 1988.

[39] NLREG-Nonlinear Regression Analysis Program, Copyright P.H. Sherrod, 6430 Annandale Cove Brentwood, TN, USA, 1995. http://www.nlreg.com.

[40] E. Block, X.J. Cai, P.C. Uden, X. Zhang, B.D. Quimby, J.J. Sulliban, Pure Appl. Chem. 68 (1996) 937. 